\title{
PENYEGARAN MATERI AJAR PECAHAN DAN PENDAMPINGAN PENGGUNAAN GEOGEBRA BAGI GURU SD DI DESA GUBUG TABANAN
}

\author{
Gst Ayu Mahayukti ${ }^{1}$, I Nyoman Sukajaya ${ }^{2}$, I Gst Putu Sudiarta ${ }^{3}$ \\ 1,2,3 Jurusan Matematika, Universitas Pendidikan Ganesha \\ email: gustiayumahayukti@undiksha.ac.id, nyoman.sukajaya@undiksha.ac.id, \\ gussudiarta@undiksha.ac.id
}

\begin{abstract}
Abstrak
Mengingat materi matematika sangat abstrak, maka guru seyogyanya menyajikan materi matematika secara bermakna dan menarik. Salah satu upaya untuk menciptakan pembelajaran yang menarik dan mudah dipahami siswa adalah dengan memanfaatkan aplikasi Geogebra, karena Geogebra dilengkapi dengan fasilitas animasi dan gerakan manipulasi,yang memudahkan guru untuk untuk memberikan pengalaman visual kepada siswanya. Tujuan dari kegiatan pengabdian ini adalah untuk meningkatkan penguasaan guru dalam pembelajaran pecahan dan penggunaan Geogebra,umlah peserta pelatihan yang hadir adalah 16 orang terdiri dari guru sebanyak 15 orang dan 1 orang kepala sekolah. Kegiatan pengabdian ini dilakukan melalui 2 kegiatan yakni pelatihan dan pendampingan. Pelatihan dilaksanakan melalui pemaparan materi pecahan dan Geogebra oleh narasumber, diskusi/tanya jawab, demontrasi penggunaan Geogebra dan pendampingan. Evaluasi dilakukan dengan tes dan proses. Hasil dari pelatihan dan pendampingani menunjukkan bahwa penguasaan materi pecahan, meningkat jika dibandingkan rata-rata skor pretest dan posttest. Peserta juga sangat antusias diskusi maupun mengajukan pertanyaan dan memberikan tanggapan. Respon guru yang dijaring melalui angket tergolong positif. Dengan demikian kegiatan pengabdian ini tergolong berhasil.
\end{abstract}

Kata kunci: Pecahan, Geogebra \& Pendampingan

\begin{abstract}
The purpose of this service activity is to improve teacher mastery in learning fractions and using Geogebra. Each training participant was represented by 3 teachers in each elementary school in the village of Gubug Tabanan and 1 supervisor. The number of training participants who attended was 16 people consisting of 15 teachers and 1 school principal. This service activity is carried out through 2 activities, namely training and mentoring. The activity was carried out through the presentation of the material on fractions and Geogebra by resource persons, discussions/questions and answers, demonstrations on the use of Geogebra and mentoring. Evaluation is done by tests and processes. The results of the training and mentoring showed that the mastery of fractions material increased when compared to the average pre-test and post-test
\end{abstract}


scores. Participants were also very enthusiastic about the discussion as well as asking questions and providing feedback. The teacher's response that was captured through a questionnaire was also quite positive. Thus, this service activity is classified as successful

Keywords: fraction number learning, Geogebra dan mentoring

\section{PENDAHULUAN}

Sebagian besar hasil penelitian menunjukkan bahwa siswa sangat lemah pada penguasaan materi pecahan yang ditunjukkan dari hasil penelitian Nuraini, dkk (2016:168); Isik \& Kar (2012), dan (Saputro, 2016:63) diungkapkan bahwa siswa benyak melakukan kesalahan operasi hitung, kesalahan konsep dan kesalahan pada keterampilan proses. Untuk membenahi ini tentu yang harus lebih dahulu dibekali adalah gurunya sesuai dengan undang-undang guru.

Selama ini guru membelajarakan siswanya dengan menulis di papan tulis, dan menggunakan media atau alat perga yang ada di sekitarnya. Tetapi, situasi tersebut tentu tidak dapat lagi dilakukan saat pembelajaran daring. Hal tersebut menyebabkan beberapa guru kebingungan dalam memilih media yang bisa digunakan dalam pembelajaran daring. Menurut Piaget, siswa SD masih berada pada tahap operasional konkret, oleh karena itu siswa sulit memahami atau menerima suatu konsep matematika yang diajarkan secara abstrak. Pada masa pandemi ini ada kecenderungan guru hanya menyampaiakn materi melalui whartshap dan kadang-kadang mengirimkan video pembelajaran tanpa menggunakan media yang dapat membantu visualisai dari konsep abstrak yang dibahas dalam hal ini pecahan. Pembelajaran matematika akan bermakna jika guru dapat menstimulus siswa untuk terlibat aktif dalam pembelajaran dengan memanfaatkan media yang tepat.

Pecahan merupakan salah satu kajian inti dari kurikulum matematika SD, dan merupakan materi yang kompleks dan sulit, apalagi bagi siswa SD. (Pujiati \& Agus, 2011) mengungkapkan bahwa kebanyakan guru masih kesulitan dalam melaksanakan pembelajaran agar bermakna, ada karena penguasaan materinya masih lemah seperti pada bilangan bulat dan operasinya, dan pecahan. Oleh karena itu dibutuhkan langkah-langkah yang efektif dalam membelajarkannya. Salah satu upaya agar ide-ide matematika dapat divisualisasi maka dapat dimanfaatkan software Geogebra. Penggunaan Geogebra dalam pembelajaran dapat mengurangi miskonsepsi dan terjadi interaksi aktif antara guru dan siswa (Zulnaidi \& Oktavika, 2018), meningkatkan hasil belajar dan meningkatkan minat siswa dalam mempelajari matematika (Arbain \& Shukor, 2015).

Sebagai mitra dalam pelaksanaan P2M ini adalah kepala SD N 4 dan 5 di desa Gubug Tabanan. Dari analisi situasi ditemukan guru masih kesulitan dalam memmbelajarkan materi pecahan. Faktor penyebabnya adalah lemahnya penguasaan materi pecahan oleh guru, juga dalam penggunaan 
media, sehingga guru belum memikirkan atau mendorong siswa untuk melakukan konstruksi sendiri pengetahuannya melalui penggunaan media yang tepat. Permasalahan lainnya adalah dalam menanamkan pengertian pecahan, dan membuat soal cerita jika diberikan suatu operasi hitung pecahan.

Para guru umumnya guru saat menjelaskan pengertian pecahan menggunakan potongan pitza atau memotong buah apel, tetapi jika menyangkut operasi hitung pecahan hanya menekankan pada perkalian silang saja tanpa memperhatikan adanya faktor persekutuan. Adanya peraturan yang mengharuskan pembelajaran secara daring menyebabkan tidak semua guru dapat melaksanakan pembelajaran secara maksimal sesuai taraf beripikir siswanya, alasannya adalah kurang dalam penguasaan teknologi. Hal ini bertentangan dengan pendapat Sukayati \& Marfuah (2009) yang menyatakan bahwa pembelajaran matematika di SD harus sesuai dengan tahap berpikir siswa, karena siswa pada tahap operasional konkret sangat membutuhkan digunakannya media/alat peraga, hal ini juga sesuai juga dengan teori Bruner bahwa belajar matematika melalui tiga tahapan yakni enaktif, ikonik dan simbolik (Suherman, dkk, 2003).

Adapun permasalahan mitra yang prioritas untuk diselesaikan adalah sebagai berikut. 1) Lemahnya penguasaan guru pada materi pecahan. Guru sudah mampu melakukan operasi pecahan dengan baik namun mereka kurang memahami konsep dibalik operasi yang dilakukan,
2) Guru belum mengetahui apa itu Geogebra dan penggunaannya. Bentuk kegiatan yang dilakukan adalah penyegaran materi ajar pecahan, dan pendampingan penggunaan Geogebra, karena pelatihan terkait penggunaan Geogebra sudah banyak dilakukan seperti yang dilakukan oleh Habinuddin et al. (2016), dan Priwantoro, Fahmi, dan Ariesta (2019). Tujuan yang ingin dicapai melalui kegiatan ini adalah untuk meningkatkan pengusaan guru SD dalam hal pembelajaran pecahan dan penggunaan Geogebra dalam pembelajaran pecahan.

\section{METODE}

Teridentifikasinya kelemahan guru di sekolah mitra dalam materi ajar pecahan, dan media Geogebra serta strategi pembelajarannya mendorong kepala sekolah untuk segera melakukan upaya guna menanggulanginya. Sehubungan dengan itu, kepala SDN 4 Gubug berharap pada LP2M Undiksha mengadakan pengabdian berupa penyegaran materi ajar pecahan dan penggunaan Geogebra daalm pembelajaran, dengan harapan penguasaan guru dalam materi pecahan meningkat, dan menambah wawasan guru terkait software Geogebra.

Menjawab permohonan kepala SDN 4 Gubug, maka kerangka pemecahan masalah yang ditempuh adalah: (i) mengidentifikasi permasalahan dan kebutuhan yang diperlukan oleh guru sekolah mitra dalam pembelajaran pecahan dan penggunaan software Geogebra, (ii) menyusun materi pelatihan "Pembelajaran Pecahan di SD dan 
Jurnal Widya Laksana, Vol.11, No.1, Januari 2022

penggunaan Geogebra," (iii) melaksanakan pelatihan sesuai jadwal yang ditentukan, (iv) guru yang telah mengikuti pelatihan diminta untuk mengimplementasikan materi yang didapat pada pembelajaran di kelas, (vi) di akhir program, diadakan evaluasi secara keseluruhan untuk mengetahui tingkat keberhasilan program, dan pendampingan ke sekolah-sekolah.

Sasaran dari kegiatan ini adalah 3 orang guru dari masingmasing SD di desa Gubug Tabanan dan 1 orang pengawas. Karena ada 5
SD di desa Gubug, maka jumlah guru yang diundang sebanyak 15 orang. Dengan demikian sasaran kegiatan ini berjumlah 15 orang guru, 1 orang pengawas, di sehingga total peserta yang diundang adalah 16 orang.

Metode dan strategi yang digunakan dalam kegiatan ini melalui penyampaian informasi, tanya jawab, dan diskusi, praktek, demontrasi dan pendampingan.Rancangan evaluasi berupa evaluasi proses dan produk seperti pada Tabel 01.

Tabel 01. Aspek, dan Kreteria Keberhasilan

\begin{tabular}{|c|c|c|c|c|}
\hline No & Aspek & $\begin{array}{c}\text { Data yang } \\
\text { Dikumpulkan }\end{array}$ & $\begin{array}{c}\text { Alat } \\
\text { Pengumpul } \\
\text { Data }\end{array}$ & Kriteria Keberhasilan \\
\hline \multirow[t]{2}{*}{1.} & Proses & Kehadiran peserta & Absen Peserta & $\begin{array}{l}100 \% \text { peserta hadir secara } \\
\text { penuh }\end{array}$ \\
\hline & & $\begin{array}{l}\text { Aktivitas peserta } \\
\text { dalam kegiatan }\end{array}$ & $\begin{array}{l}\text { Lembar } \\
\text { observasi }\end{array}$ & $\begin{array}{l}60 \% \text { peserta aktif selama } \\
\text { pelatihan seperti bertanya, } \\
\text { dan memberi tanggapan }\end{array}$ \\
\hline 2. & Produk & $\begin{array}{l}\text { Tingkat } \\
\text { penguasaan } \\
\text { materi pecahan } \\
\text { Respon peserta } \\
\text { terhadap } \\
\text { pelaksanaan } \\
\text { kegiatan }\end{array}$ & $\begin{array}{l}\text { pre tes dan post } \\
\text { tes }\end{array}$ & $\begin{array}{l}70 \% \text { peserta } \\
\text { penguasaannnya baik } \\
\text { Respon peserta positif }\end{array}$ \\
\hline
\end{tabular}

\section{HASIL DAN PEMBAHASAN}

Hasil pelaksanaan kegiatan pengabdian dipaparkan seperti berikut ini. Jumlah guru yang hadir dalam pelatihan ini adalah 15 orang dan 1 orang kepala sekolah, sehingga target kehadiran memenuhi target. Acara ini dibuka secara resmi oleh Sekretaris LP2M Undiksha bapak Dr. I Made Sugiarta, M.Si. Dalam sambutannya Pak Made menyampaikan terima kasih atas berlangsungnya kegiatan pengabdian ini. sehingga permasalahan yang dihadapi oleh guru SD di desa Gubug bisa segera teratasi. Juga disampaikan tentang pentingnya memiliki keterampilan abad 21 oleh seorang guru, agar dapat melaksanakan pembelajaran daring denagn bermakna, karena ditenggarai banyak guru ataupun siswa yang 
bermasalah dengan penggunaan teknologi.

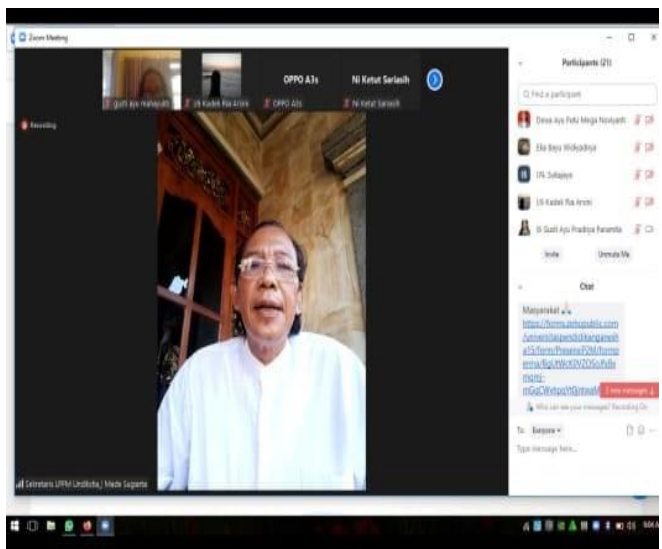

Gambar 1. Sambutan dari Sekretaris LP2M

Setelah pembukaan dilanjutkan dengan pre-test dengan soal sebagai berikut.

1. Apa arti a, b berturut-turut pada pecahan $\frac{a}{b}$

2. Hitunglah
a. $\frac{3}{4}+\frac{2}{5}$
b. $\frac{1}{4}-\frac{4}{6}$
c. $\frac{2}{5}-\frac{3}{10}$

3. Nyatakan soal matematika berikut dalam soal cerita!

a. $\frac{2}{3} x \frac{1}{5}$
b. $\frac{1}{2} x 2$

Berdasarkan hasil analasis terhadap jawaban peserta, diperoleh hasil untuk soal nomer satu semua peserta menjawab dengan benar, soal $2 \mathrm{a}$, dan $2 \mathrm{c}$ semua peserta menjawab dengan benar lengkap sesuai tuntutan indikator, tetapi ada 3 orang peserta hanya menulis hasilnya saja, untuk nomer $2 b$ hanya 3 orang menjawab menggunakan konsep KPK, 3 orang hanya menulis hasilnya, sisanya hanya menyamakan penyebut dengan hasil silang. Sedangkan untuk soal nomor 3 hampir $65 \%$ salah dalam mengubahnya menjadi soal cerita, dan ada satu orang peserta yang tidak mengirimkan jawabannya.

Sesi I adalah pemaparan materi oleh Narasumber Dr. I Nyoman Sukajaya, M.T terkait Pembelajaran Abad 21 (Gambar 2) dan pembahasan soal pretest (Gambar 3).

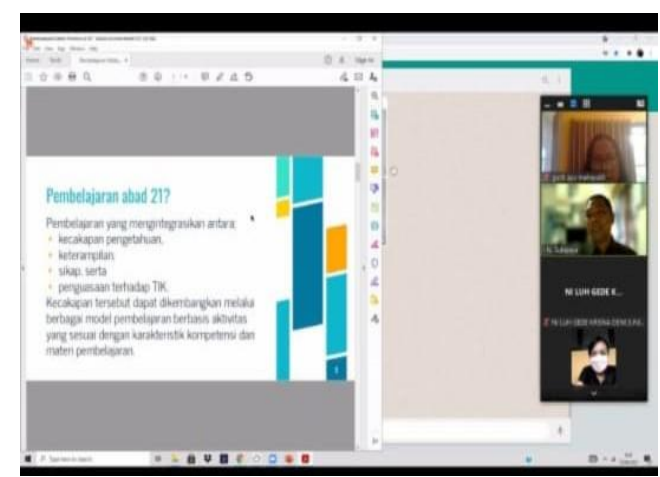

Gambar 2. Pemaparan Pembelajaran Abad 21

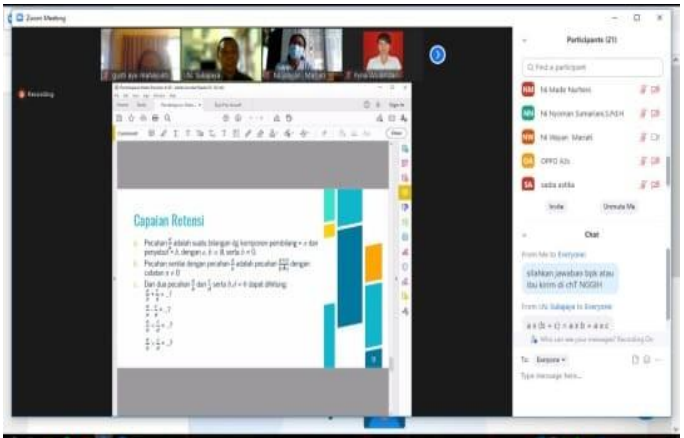

Gambar 3. Pembahasan soal Pretest

Narasumber juga menyampaikan pentingnya melatih siswa menyelesaikan soal HOTS yang melibatkan pecahan seperti disajikan pada Gambar 4. 


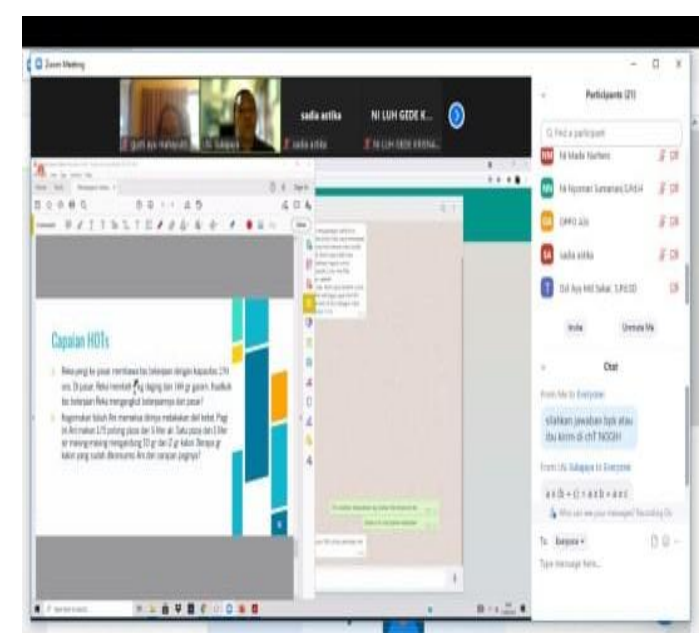

Gambar 4. Pemaparan soal HOTS

Dilanjutkan pemaparan tentang media Geogebra dan penggunaannya dalam menanamkan konsep pecahan seperti pada Gambar 5, 6 dan 7.

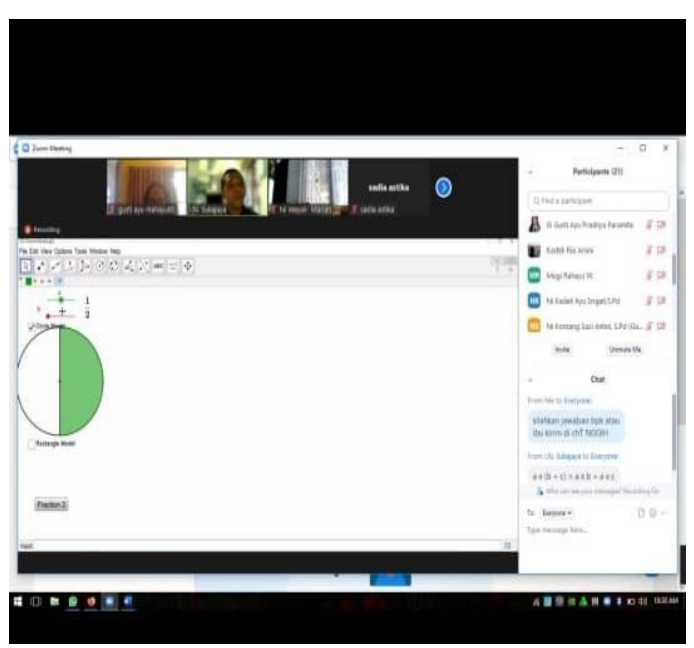

Gambar 5. Pengunaan Geogebra dalam menjelaskan pengertian Pecahan

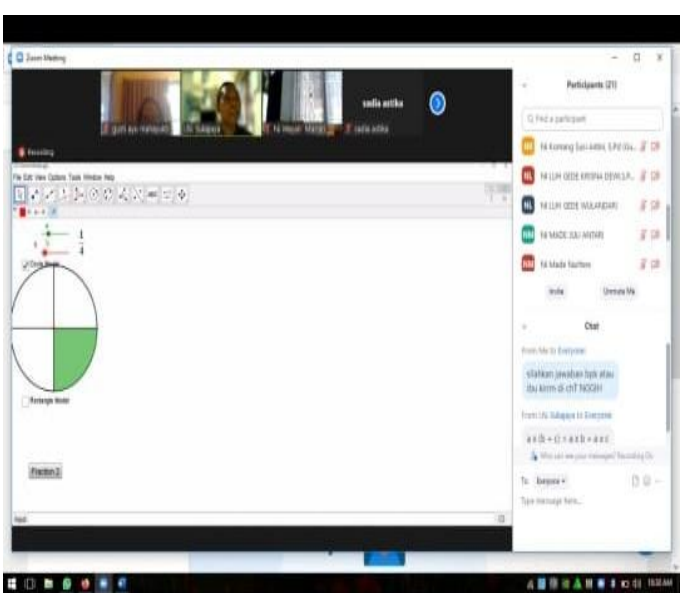

Gambar 6. Dengan mengerakan kursor siswa dapat berkreasi

Selain itu, pada Gambar 7 disampaikan juga bagaimana menggunakan Geogebra untuk melakukan operasi hitung pecahan.

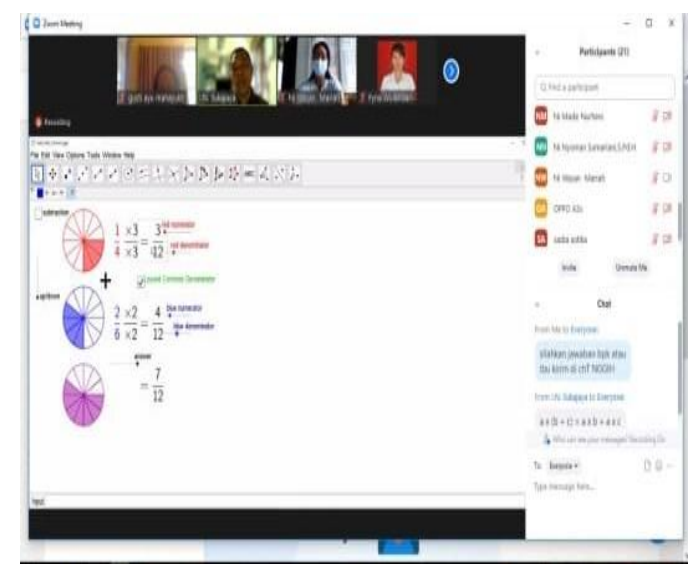

Gambar 7. Operasi Hitung Pecahan

Pada sesi diskusi dan tanya jawab, ada 4 peserta yang bertanya yang diawali oleh penanya 1 , lbu $\mathrm{Ni}$ ketut Sariasih selaku Kepala SD N 4 Gubug, dalam pembelajaran kan penting penanaman konsep terapi saat ujian hanya diperlukan jawabannya saja, bagaimana itu bapak narasumber? dan Penanya II, Bu Mugi 
Jurnal Widya Laksana, Vol.11, No.1, Januari 2022

Rahayu dari SD N 3 Gubug mengajukan pertanyaan tentang sulitnya membelajarkan soal pemecahan masalah pada siswa, karena siswa kurang tertarik mengerjakannya sebab saat UTS siswa diberikan soal pilihan ganda, bagaimana tanggapan bapak narasumber? Penanya ketiga dari ibu Feny Wulandari dari SDN 1 Gubug, pertanyaannya hampir mirip dengan bu sariasih bahwa siswa sering jika diberikan soal uraian,siswa hanya menuliskan hasilnya saja, sehingga sulit mengukur tercapai tidaknya indikator yang dibuat.

Ketiga pertanyaan ditanggapi oleh narasumber sebagai berikut bahwa jika menggunakan teknologi jelas itu tidak diminta penanaman konsep saja, tetapi pada keterampilan komputasi, tetapi jika guru beralibi akan yang dipentingkan jawabannya saja, memang benar ini karena soal kan untuk yg pilihan ganda, tetapi jika ingin mengetahui apakah siswa itu paham atau mampu berkritis tidak cukup dengan pilihan ganda, karena belajar atau sekolah bukan melulu hanya memperoleh nilai bgus tetapi pemahaman siswa, kemampuan berpikir kritis, kreatif, kemampuan pemecahan masalah juga harus baik, karena itu tetap perlunya penanaman konsep.

Penanya ke 4 oleh Ibu Yunita Dewi dari SDN 5 Gubug, bertanya jika dalam pembelajaran matematika menggunakan software Geogebra, fasilitas sekolah tidak mendukung, dan kami para guru juga belum mengetahui dan tertarik, bagaimana solusinya? Narasumber menjawab bahwa ini pentingnya pendampingan setelah pertemuan daring ini.

Pada sesi ketiga diisi dengan postest.

Sesi Postest

1. Tuliskan makna pembilang dan penyebut pada pecahan: $\frac{4}{5}$

2. Nyatakan soal matematika berikut dalam soal cerita!
a. $\frac{2}{3} x \frac{1}{5}$
b. $\frac{1}{2} \times 2$

Hasil analisis pekerjaan peserta saat postest diperoleh hasil untuk soal nomer 1 ada $72,72 \%$ yang benar, ada $22,78 \%$ yang salah, nomer 2 a sebesar $45,45 \%$ yang benar, sedangkan yang salah $54,55 \%$, untuk soal nomer $2 \mathrm{~b}$ didapatkan $81,81 \%$ benar dan $18,19 \%$ masih salah.

Pada akhir sesi ketiga, juga dikumpulkan pula data respon peserta terhadap pelaksanaan pelatihan, dan hasilnya menunjukakan $100 \%$ peserta mengganggap pelatihan ini penting dan narasumer menguasai materi, dan 81 , $25 \%$ berharap kegiatan ini dilanjutkan.

Pelaksanaan

kegiatan pengabdian kepada masyarakat telah berjalan dengan baik, dan mampu meningkatkan penguasaan guru pada materi pecahan dan strategi pembelajarannya. Berdasarkan registrasi peserta diperoleh bahwa semua guru yang diundang yakni sebanyak 15 guru hadir, 1 orang pengawas yang diundang berhalangan hadir, tetapi 1 orang kepala sekolah ikut sebagai peserta. Dengan demikian persentase target yang ditetapkan terpenuhi adalah $100 \%$. Peserta mengikuti pelatihan secara penuh, dan antusias, tampak dari perhatian mereka saat narasumber memaparkan 
materinya, meski ada peserta keluar masuk karena gangguan sinyal atau penggunaan laptop secara bergiliran. Begitu pula ketika sesi diskusi, peserta aktif mengikuti dan beberapa guru aktif bertanya.

Hasil pre tes dan post tes menunjukkan bahwa kegiatan pelatihan telah mampu meningkatkan penguasaan peserta pada materi pecahan dan strategi pembelajarannya. Sebelum mengikuti pelatihan, peserta kurang memahami bagaimana mengubah soal operasi hitung pecahan menjadi soal cerita atau belum mampu mengkaitkan operasi pecahan dengan konteks kehidupan nyata, sedang untuk menyebutkan arti $a$ dan $b$ pada pecahan $a / b$ saat pretest semua benar, sedangkan saat postest ada yang masih salah. Banyak di antaranya yang mendefinisikan pecahan sebagai "operasi bagi dua bilangan bulat" dan tentu hal tersebut tidak tepat. Saat postest meski ada peserta yang belum mampu mengkaitkan operasi pecahan dengan konteks kehidupan nyata. Peserta masih ada yang kesulitan untuk membuat soal cerita, demikian juga $100 \%$ peserta menyatakan belum mengetahui tentang media Geogebra dan penggunaannya dalam pembelajaran.

Hasil pendampingan juga menunjukkan hasil yang baik, peserta yang sehari-harinya memang mengajar matematika atau tertarik dengan pelajaran matematika sangat antusias minta didampingi, dalam penggunaan Geogebra, karena seperti diketahui penggunaan Geogebra dapat meningkatkan pengetahuan konseptual dan prosedural (Alkhateeb and AlDuwairi 2019), dapat menjelaskan konsep perbandingan pecahan (Poon 2018). Selain itu dari aspek afektif, penggunaan Grogebra dapat meningkatkan keyakinan dalam memecahkan masalah matematika (Mthethwa et al. 2020), memberikan sikap positif pada pembuktian matematika (Zengin 2017), dan meningkatkan minat siswa dalam mempelajari matematika (Arbain and Shukor 2015).

Secara umum program pengabdian pada masyarakat ini telah mampu memecahkan permasalahan yang dihadapi peserta berkaitan dengan endahnya penguasaan peserta pada materi ajar pecahan dan strategi pembelajarannya. Kepala SDN 4 Gubug, pada kegiatan penutupan mengharapkan kegiatan pengabdian seperti ini bisa berlangsung secara kontinu dengan melibatkan guru yang lebih banyak.

\section{KESIMPULAN}

Setelah mengikuti pelatihan ini peserta mendapatkan pencerahan dan semangat baru dalam membelajarakan pecahan menggunakan Geogebra. Pelatihan penggunaan Geogebra ini hal baru bagi peserta, sehingga peserta sangat tertarik dan segera minta didampingi biar lebih mengerti dalam penggunaannya di kelas daring

\section{DAFTAR PUSTAKA}

Alkhateeb, Ahmad,M and Al-Duwairi, A, M.. 2019. The Effect of Using Mobile Applications (GeoGebra and Sketchpad) on the Students' Achievement. International Electronic Journal of Mathematics Education 
Jurnal Widya Laksana, Vol.11, No.1, Januari 2022

14(3):523-33.

10.29333/iejme/5754.

Arbain, Nazihatulhasanah, and Nurbiha A. Shukor. 2015. The Effects of GeoGebra on Students Achievement. Procedia - Social and Behavioral Sciences 172(2007):208- $14 . \quad$ doi: 10.1016/j.sbspro.2015.01.356.

Habinuddin, E., Sartika, E., Suryani, A., Murniati, S., \& Binarto, A. 2016. Peningkatan Keterampilan Penggunaan Software Guru SMP Cimahi the Skill Improvement of Using Geogebra Software in Mathematics Learning for Junior High School (SMP) Teachers in Cimahi.Sigma-Mu, 8(1):7-16. Tersedia pada

Isik, C. \& Kar, T. 2012. An Error Analysis in Division Problems in Fractions Posed by Pre-Service. Educational Sciences: Theory \& Practice, 12(3): 2303-2309. Tersedia pada https://files.eric.ed.gov/fulltext/E J1000919.pdf

Kementerian Pendidikan dan Kebudayaan. 2012. Kebijakan Pengembangan Profesi Guru. Badan PSDMPK-PMP, Jakarta

Mthethwa, Mthembeni, Bayaga, A., Bossé, M. J. and Williams, D. 2020. Geogebra for Learning and Teaching: A Parallel Investigation. South African Journal of Education, 40(2):1$12 . \quad$ doi: 10.15700/saje.v40n2a1669.
Nuraini, N.L.S., Suhartono, \& Yuniawatika. 2016. Kesalahan Siswa pada Operasi Penjumlahan dan Pengurangan Pecahan di Kelas VI Sekolah Dasar. Sekolah Dasar: Kajian Teori dan Praktik Pendidikan, 25(2): $168 \quad-\quad 175$, http://dx.doi.org/10.17977/um00 9v25 i22016p168.

Priwantoro, Soffi Widyanesti, Syariful Fahmi, and Dian Ariesta Y. 2019. Pelatihan Peningkatan Kemampuan It Bagi Guru Matematika Menggunakan Geogebra. Jurnal Terapan Abdimas, 4(2):203. Tersedia pada

doi: 10.25273/jta.v4i2.4847.

Pujiati dan Agus S. 2011. Pembelajaran $F P B$ dan KPK di SD. P4TK Matematika, Yogyakarta.

Saputro, B.A. 2016. Kemampuan Penalaran Matematis Siswa yang Belajar Operasi Pecahan Menggunakan Permainan Tradisional. Jurnal Penelitian dan Pembelajaran Matematika, 9(1): $63 \quad-\quad 72$. http://dx.doi.org/10.30870/jppm. v9i1.981.

Suherman, E., dkk. 2003. Strategi Pembelajaran Matematika Kontemporer. JICA, Bandung:

Sukayati dan Marfuah. 2009. Pembelajaran Operasi Hitung Perkalian dan pembagian Pecahan di SD. P4TK Matematika, Yogyakarta.

Zengin, Y. 2017. The Effects of GeoGebra Software on Pre- 
Jurnal Widya Laksana, Vol.11, No.1, Januari 2022

Service Mathematics Teachers' Attitudes and Views toward Proof and Proving. International Journal of Mathematical Education in Science and Technology, 48(7):1002-22.

Zulnaidi, H., \& Oktavika, E. 2018. The Effect of Geogebra onStudents'
Misconceptions of Limit Function Topic. JuKu: Jurnal Kurikulum \& Pengajaran Asia Pasifik, 6(1), 1-6. Tersedia pada 